\title{
Mixed model for estimating the effects of the Rht1 dwarfing allele, background genes, CCC and their interaction on culm and leaf elongation of Triticum aestivum L., spring wheat
}

\author{
A. BEHARAV, A. CAHANER* \& M. J. PINTHUS \\ The Hebrew University of Jerusalem, Faculty of Agriculture, Rehovot 76100, Israel
}

\begin{abstract}
A model for the effects of a single gene (SG), background genes (BG), an environmental factor (EF) and the effects of their interactions on quantitative traits is developed. It is a mixed model where SG and EF have fixed effects while BG have a random effect. This model is applied to the analysis of the effects of the dwarfing alleles at the Rht $I$ locus (SG), interfamily variation (representing BG) and the growth regulant $\mathrm{CCC}(\mathrm{EF})$ on coleoptile, leaf and culm length of spring wheat. Culm length of $\mathrm{F}_{7}$ families was tested in a field experiment in the absence of lodging. Coleoptile and leaf lengths of $\mathrm{F}_{9}$ seedlings were examined in a growth room at $18^{\circ} \mathrm{C}$. Each family was descended from a single $\mathrm{F}_{5}$ plant, heterozygous at the $R h t I$ locus. Within each family the homozygous tall $(r h t l)$ and the homozygous semi-dwarf $(R h t I)$ genotypes were identified. Thus, comparing nearly isogenic genotypes within random families in advanced generations enabled the estimation of all the main effects and interactions between SG, BG and EF. The restricted maximum likelihood (REML) method was used in the analysis of variance.

In all the three organs CCC caused significant shortening which was somewhat greater in the rht 1 than in the Rhtl genotype and the CCC $\times R h t l$ interaction effect on culm length was significant. Considerable and significant interfamily variation was found for all three characters. A significant $\mathrm{CCC} \times$ family interaction effect on the length of the first leaf was obtained. This interaction effect was of a specific trend indicating a distinct increase in the response to $\mathrm{CCC}$ with greater leaf length. No CCC $\times R h t l \times$ family or $R h t I \times$ family interaction effects were detected. The use of two graphical/analytical methods proved to be complementary for a complete evaluation of two-way interactions $(\mathrm{CCC} \times$ families and $\mathrm{CCC} \times R h t l$ in the present study).
\end{abstract}

Keywords: environmental factor, interaction, polygene, quantitative trait, single gene.

\section{Introduction}

Many quantitative traits (QT) are known to be controlled by one or more single genes of major effect $(\mathrm{SG})$ as well as by variation in background (BG) which is akin to the polygene (PG) system discussed by Falconer (1981) and by Mather \& Jinks (1971).

The existence of interactions between genotypes and environmental factors has long been recognized (Fisher \& Mackenzie, 1923). Various methods have been proposed for the statistical analysis of these interactions (Freeman, 1973). An experimental design for

${ }^{*}$ Correspondence. self-pollinating plants - consisting of individuals, each belonging to a specific $\mathrm{F}_{3}$ family which segregates for a SG - and the corresponding statistical procedures were developed by Elkind \& Cahaner (1986) to estimate the components of a mixed model which includes the effects of SG, PG and their interaction.

A modification of this design for advanced generations has been applied by Beharav et al. $(1988,1992)$. This report presents the application of a mixed model which enables the estimation and the analysis of the main effects and interaction effects of an environmental factor (EF) in addition to those of the SG and $\mathrm{BG}$, which have already been dealt with in a previous report (Beharav et al., 1992). This was achieved in a 
study of the effects of the growth regulant CCC (EF) on leaf and culm elongation of the tall $(r h t l)$ and semidwarf $(R h t l)$ genotypes (SG) in each of 25 or 30 advanced generation spring wheat families (representing BG).

$\mathrm{CCC}$ (chlormequat) is a growth retardant inhibiting GA biosynthesis (Roberts \& Hooley, 1988). Owing to its shortening effect on wheat culms, it is occasionally applied to prevent lodging of this crop. In most modern semi-dwarf wheat cultivars the short stature is due to one of two height-reducing genes, Rhtl and Rht 2 , introduced from the dwarf Japanese cv. 'Norin 10' (Gale \& Youssefian, 1985). Culm length of wheat is furthermore controlled by many polygenes (Allan et al., 1968). A weaker response to CCC of semi-dwarf (Rhtl or $R h t 2$ ) lines than of their near-isogenic tall lines was demonstrated in a study with winter wheat (Gale \& Youssefian, 1983). This study, however, did not enable an estimate of the interactions between CCC, Rht alleles and BG and between CCC and BG, which has been attempted in the present investigation.

\section{Experimental population}

The families examined were progenies of a random sample of single $F_{5}$ plants of 'Mivhor' $\times$ 'Lakhish', heterozygous at the Rhtl locus. The parental cultivars are high-yielding semi-dwarf spring wheats differing in their dwarfing alleles ('Mivhor' (Penjamo Sib $\times$ Gabo 55) carrying Rhtl and 'Lakhish' (Yaktana $\times$ Norin $10-$ Brevor $) \times($ Florence $\times$ Aurore $)$ carrying $R h t 2)$. Bulked $\mathrm{F}_{2}, \mathrm{~F}_{3}, \mathrm{~F}_{4}$ and $\mathrm{F}_{5}$ populations were grown without any deliberate selection. The heterozygosity of the $\mathrm{F}_{5}$ plants was confirmed by testing the seedlings, from a sample of $F_{6}$ seeds from each $F_{5}$ plant, by a GA response test (Gale \& Gregory 1977). The assessment in each family of the $R h t$ dwarfing allele (whether $R h t I$ or $R h t 2$ ) was based on test crossing with the homozygous $R h 2 \mathrm{cv}$. 'Lakhish'. Due to insufficient amounts of seed the $R h t 2$ families (in which the semi-dwarf genotype was rhtlrhtl $R h t 2 R h t 2$ ) were excluded from the experiments reported here. In each $R h t l$ family the seeds from all the $F_{6}$ plants which had been identified by a seedling GA response test as homozygous tall ( $r h t 1$ rht 1 rht 2 rht 2 ) were bulked separately and likewise all the seeds of the plants which had been identified as homozygous semi-dwarf (Rhtl Rhtl rht2 rht2). These bulks comprised the $F_{7}$ seed of the respective two Rhtl genotypes in each family (seeds from the heterozygous $\mathrm{F}_{6}$ plants were discarded).

\section{Experimental procedures and measurements}

Culm lengths of $30 \mathrm{~F}_{7}$ families were determined at the Lakhish Experiment Farm (1988) in a field which was adequately fertilized and kept free of weeds, diseases and lodging. Seasonal rainfall and irrigation amounted to $582 \mathrm{~mm}$. The experiment consisted of two blocks in a split-plot design. The combinations of the two Rhtl genotype groups (tall and semi-dwarf) and the two levels of $\mathrm{CCC}$ (treatment and control) comprised the four main plots in each block. The sub plots were 30 rows, one of each family, each row $150 \mathrm{~cm}$ long at a spacing of $30 \mathrm{~cm}$ between rows and $2 \mathrm{~cm}$ within rows. CCC $\left(0.4 \mathrm{~g} \mathrm{~m}^{-2}\right)$ was applied twice in aqueous sprays, at intervals of 5 days during the period of the elongation of the first and the second culm internodes.

Coleoptile and first leaf lengths of seedlings of $25 \mathrm{~F}_{9}$ families (descendents of the above mentioned $F_{7}$ families but excluding five of them) were examined in a growth room at a constant temperature of $18^{\circ} \mathrm{C}$ and continuous light of $200 \mu \mathrm{mol} \mathrm{m}{ }^{-2} \mathrm{~s}^{-1} \mathrm{PAR}$ at seedling level, in a split-plot design with four randomized blocks. Seeds were sown in $34 \times 24 \times 7 \mathrm{~cm}$ trays filled with vermiculite saturated with 2.751 of $6.34 \times 10^{-4} \mathrm{M}$ (100 p.p.m.) aqueous CCC solution or 2.751 water for the control treatment. In each block the four combinations of the two Rhtl genotype groups and the two CCC treatments were sown in different trays which comprised the main plots. Each tray contained 25 rows of 10 seedlings, one row of each of the 25 families as a subplot. After sowing the trays were kept for 3 days at $3-4^{\circ} \mathrm{C}$ to ensure uniform germination before being moved to a growth room where they were watered as needed. Seedlings were harvested at the time of emergence of the tip of the third leaf, which occurred at the age of 21 days.

\section{The model}

The effects on the traits examined comprised the following components:

$$
\begin{aligned}
\mathrm{SG} & +\mathrm{BG}+\mathrm{EF}+(\mathrm{SG} \times \mathrm{BG})+(\mathrm{SG} \times \mathrm{EF}) \\
& +(\mathrm{BG} \times \mathrm{EF})+(\mathrm{SG} \times \mathrm{BG} \times \mathrm{EF}) .
\end{aligned}
$$

This model represents a general mixed model which combines the effects of SG, BG and an EF. The SG is assumed to have two alleles $(S, S)$ and three genotypes $(S S, S s, s s)$, of which the two homozygous ones were considered in this study. The variation among the $\mathrm{BG}$ is obtained by random sampling of families from a population segregating for the BG. There should be two or more levels of EF, representing various growth environments or various treatments of a given factor in the same environment. The interactions are tested by a three-way factorial ANOVA with the SG, the families and the EF as factors. The effects of the SG, EF and the interaction between them $(\mathrm{SG} \times \mathrm{EF})$ are regarded as 'fixed', the aim being to estimate the means of the 
various levels of each of them, while the effects of the other components of the model are considered 'random', the aim being to estimate their variances.

In the present study $R h t l$ is the SG represented by two genotypes (the semi-dwarf $R$ htl $/ R$ htl and the tall $r h t 1 / r h t 1$ ), CCC is the $\mathrm{EF}$ (with two levels: treatment and control) and BG are represented by the different families.

\section{Data analysis}

A restricted maximum likelihood method (REML) was used in the analysis of variance by program $3 \mathrm{~V}$ of the BMDP package (Dixon et al., 1985). REML is considered the method of choice for variance component estimation because estimates must fall within the parameter space. Furthermore, in REML estimation all available information can be utilized (Henderson, 1984). The linear model used for analysis was:

$$
\begin{aligned}
\mathrm{Y}_{\mathrm{ijk} 1}= & \mu+\tau_{\mathrm{i}}+\alpha_{\mathrm{j}}+(\tau \alpha)_{\mathrm{ij}}+\mathrm{B}_{1}+\mathrm{E}_{\mathrm{ij} 1}^{1}+\mathrm{F}_{\mathrm{k}}+(\tau \mathrm{F})_{\mathrm{ik}} \\
& +(\alpha \mathrm{F})_{\mathrm{jk}}+(\tau \alpha \mathrm{F})_{\mathrm{ijk}}+\mathrm{E}_{\mathrm{ijk} \mathrm{kl}}^{2},
\end{aligned}
$$

where $Y_{i j k l}$ is the quantitative value of the examined trait of the subplot of family $\mathrm{k}$ with $R h t$ genotype $\mathrm{j}$ and CCC treatment $\mathrm{i}$ in block $1 ; \mu$ is the general mean; $\tau_{\mathrm{i}}$ is the effect of CCC treatment $\mathrm{i} ; \alpha_{\mathrm{j}}$ is the $R h t$ genotype $\mathrm{j}$ effect; $(\tau \alpha)$ is the $\mathrm{CCC} \times R h t$ interaction effect; $\mathrm{B}_{1}$ is the effect of block $1 ; \mathrm{F}_{\mathrm{k}}$ is the effect of family $\mathrm{k} ;(\tau \mathrm{F})$ is the $\mathrm{CCC} \times$ family interaction effect; $(\alpha \mathrm{F})$ is the $R h t$ genotype $\times$ family interaction effect; $(\tau \alpha \mathrm{F})$ is the $\mathrm{CCC} \times R h t$ genotype $\times$ family interaction effect; $\mathrm{E}^{1}$ and $E^{2}$ are error 1 and error 2 terms, respectively. Error 1 is the pooled variance, over blocks, between the combinations of CCC treatments and $R h t$ genotypes. Error 2 represents the variance between subplots within the same CCC $\times$ Rht combination and it comprises the background variation within family-Rht genotype-CCC combinations and the experimental

Table 1 Effect of CCC on culm length in the field (means from $30 \mathrm{~F}_{7}$ families) and on coleoptile and first leaf lengths of seedlings (means from $25 \mathrm{~F}_{9}$ families) in $r h t 1$ and $R h t l$ genotypes of 'Mivhor' $\times$ 'Lakhish' wheat

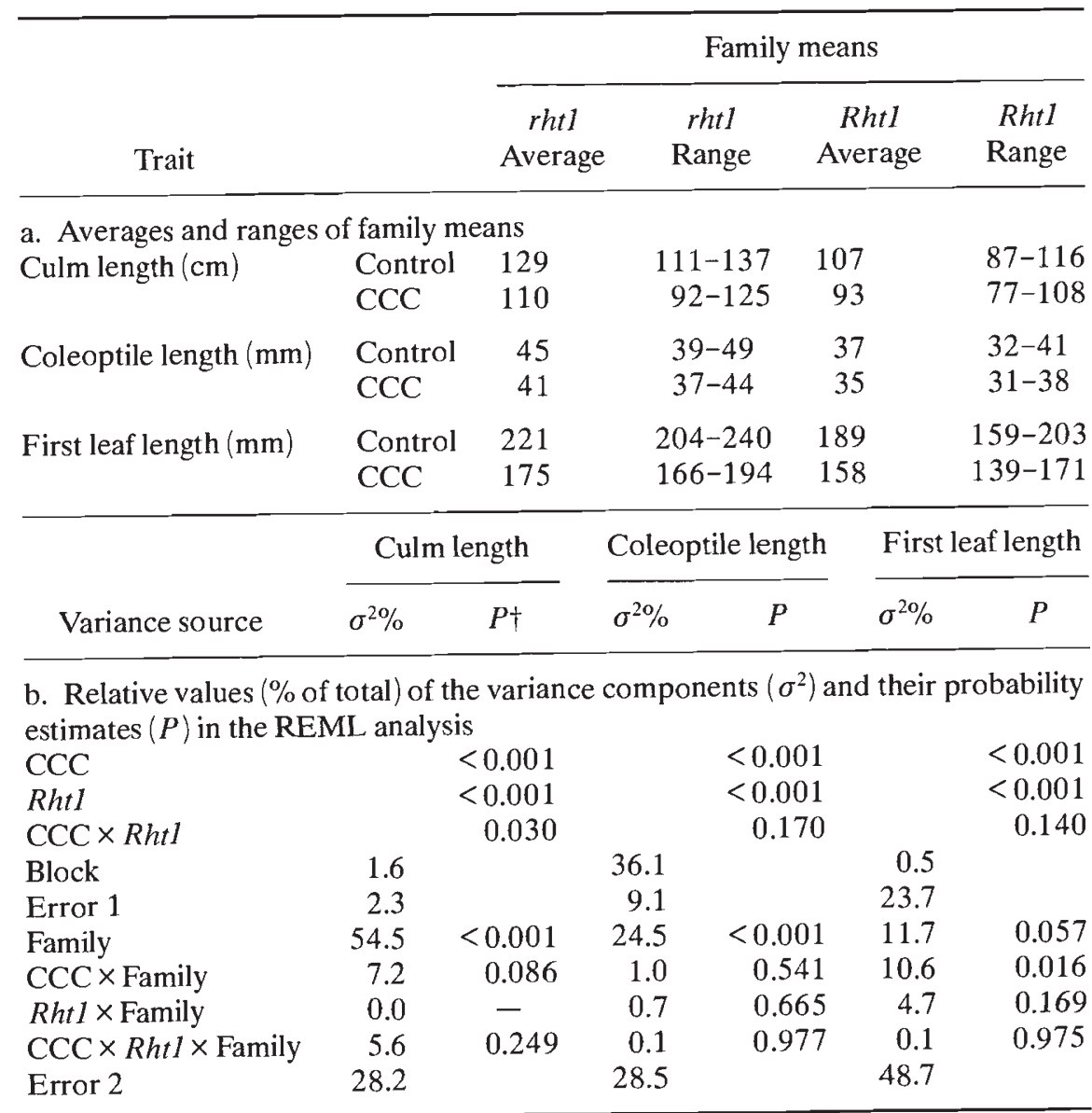

$\dagger P(F)$ for the 'fixed' effects; $P\left(\chi^{2}\right)$ for the 'random' effects. 
variation. The effects of $\mathrm{CCC}, R h t$ genotype and the interaction between them were regarded as 'fixed' and the null hypothesis that their various levels had no effect was tested by the $F$-test with $E^{1}$ as the error term. All other effects were considered 'random' and hypotheses testing was accomplished by calculating the difference between $-2 \times \log$ of maximum likelihood of the complete model and that of a model in which the tested component was absent. This difference is distributed as a chi-square with one degree of freedom (Dixon et al., 1985).

In an additional approach to detect and illustrate treatment $\times$ family interacton, means of CCC-treated plants within each family were plotted against the means of their control sibs, as suggested by Falconer (1952). The following model was used:

$\mathrm{Y}_{\mathrm{j}}=\alpha+\beta\left(\mathrm{Y}_{\mathrm{j}}^{\prime}\right)+\mathrm{E}_{\mathrm{j}}$,

where $Y_{j}$ is the mean, within family $j$, of CCC-treated plants; $\alpha$ is the mean effect of the CCC treatment; $\mathrm{Y}_{j}^{\prime}$ is the mean of the control plants in family $\mathrm{j} ; \beta\left(\mathrm{Y}_{\mathrm{j}}^{\prime}\right)$ is the regression coefficient of treated plants on their control sibs and $E_{j}$ is the random error term. Rejection of the null hypothesis of a unity slope $(\beta=1)$, tested by $t$-test (SAS Institute, 1985), indicates a significant family $\times$ treatment interaction.

\section{Results and discussion}

Averages and ranges of the family means, for the three traits tested, of the CCC treated and untreated tall $(r h t 1)$ and semi-dwarf $(R h t l)$ genotypes are presented in part a of Table 1. Hypothesis testing and variancecomponent percentages are presented in part $\mathrm{b}$ of Table 1. No significant second-order $\mathrm{CCC} \times R h t l \times$ family interaction effect on any of the tested characters was found; nor was there any significant $R h t l \times$ family interaction.

CCC had a significant shortening effect on all the three organs tested (Table 1a). This effect was somewhat weaker in the semi-dwarf $(R h t 1)$ genotype than in the tall $(r h t I)$ genotype. This $\mathrm{CCC} \times R h t$ interaction effect was significant in the case of culm length. The relative mean reductions in culm length of the $r h t 1$ and $R h t 1$ genotypes, however, were rather similar, amounting to 14.7 per cent and 13.1 per cent, respectively.

High and significant interfamily variation (i.e. genetic background variation) was found for all three traits (Table 1b) and is depicted in Fig. 1 for culm(a) and first leaf $(b)$. A significant $\mathrm{CCC} \times$ family interaction effect was found in the case of the first leaf, indicating significant interfamily variation in the response of this organ to CCC. This seems noteworthy considering the apparent lack of existing reports on genotypic dif-
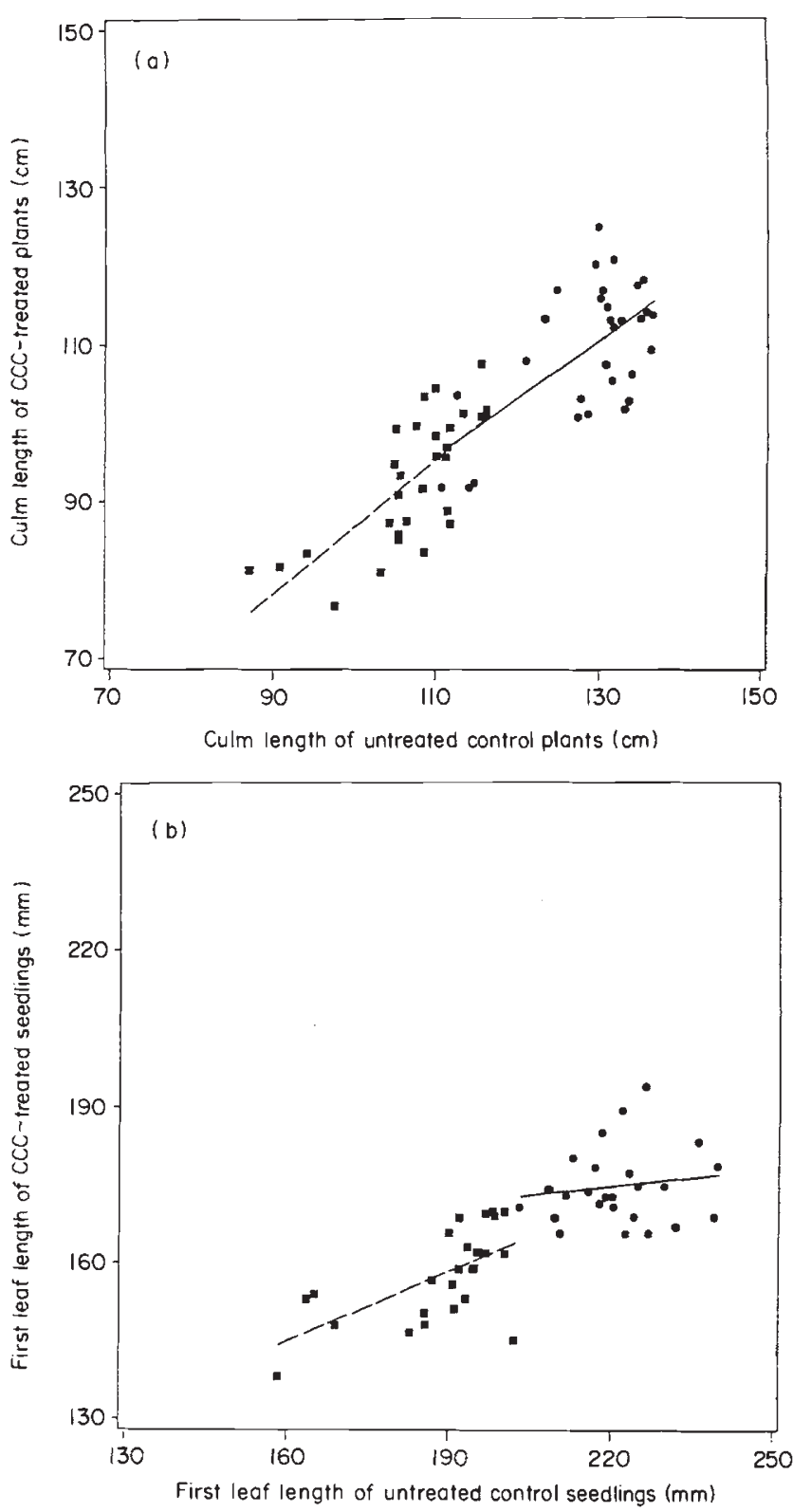

Fig. 1 Regression of mean length parameters of CCCtreated plants on untreated control plants of $\operatorname{rhtl}(\bullet-)$ and $R h t I(---)$ genotypes within different 'Mivhor' $X$ 'Lakhish' wheat families. (a) Culm length of $F_{7}$ plants; (b) first leaf length of $F_{9}$ seedlings.

Regression coefficients (slopes)

$\begin{array}{lcc}\text { rhtl } & \mathrm{a} & \mathrm{b} \\ \text { Rhtl } & 0.73 & 0.11 \\ & 0.86 & 0.45\end{array}$

ferences in response to $\mathrm{CCC}$ other than those due to the Rht alleles (Gale \& Youssefian, 1983) or varietal differences which should rather be attributed to differences in their phenological development (Pinthus, 1968). 
The graphical presentation in Fig. 1 and the corresponding statistical analyses are similar to those used to evaluate genotype $\times$ environment interaction (Falconer, 1952). The interaction of the CCC and control treatments with the families could be clearly detected by regressing the means of CCC-treated plants on the means of their control sibs over families (Fig. 1). In the case of the first leaf length, the highly significant rejection $(P<0.001)$ of the null hypothesis of $\beta=1$ indicated the interaction between families and CCC treatments in both $R h t 1$ genotypes (Fig. 1b). In the rhtl genotype the slope $(\beta=0.11)$ was not significantly different from zero, indicating that the first leaf length of CCC-treated tall plants was completely independent of the first leaf length of their untreated sibs (Fig. 1b). In contrast, Fig. 1a clearly demonstrates the lack of $\mathrm{CCC} \times$ family interaction effect on culm length. There was a good agreement between the ANOVA and the regression analyses, with the latter being more sensitive to the interactions between the fixed effects $R h t$ and CCC and the random effects of the families.

\section{Acknowledgements}

This study is based on data obtained in the Ph.D. thesis work of the senior author supported by a grant from Harry and Lillian Freedman.

\section{References}

ALLAN, R. E., VOGEL, O. A. AND PETERSON, C. J. JR. 1968. Inheritance and differentiation of semi-dwarf culm length of wheat. Crop Sci., 8, 701-704.

BEHARAV, A., PINTHUS, M. J. AND CAHANER, A. 1988. Interaction effects of the $R h t$ dwarfing alleles and polygenes on culm length and grain yield of spring wheat. In: Miller, T. E. and Koebner, R. M. D. (eds) Proceedings of the Seventh International Wheat Genetics Symposium, pp. 1047-1050. Cambridge, England.
BeHARAV, A., PINTHUS, M. J. AND CAHANER, A. 1992. Interaction effects of the $R h t 1$ and $R h t 2$ dwarfing alleles and background genes on the growth and the grain yield of spring wheat (Triticum aestivum L.). Europ. J. Agron., 1, 263-269.

DIXON, W. J., BROWN, M. B., ENGELMAN, L., FRANE, J. W., HILL, M. A., JENNRICH, R. I. AND TOPOREK, J. D. 1985. BMDP Statistical Software. University of California Press, Berkeley.

ELKIND, Y. AND CAHANER, A. 1986. A mixed model for the effects of single gene, polygenes and their interaction on quantitative traits. I. The model and experimental design. Theor. Appl. Genet., 72, 377-383.

FALCONER, D. S. 1952. The problem of environment and selection. Am. Nat., 86, 293-298.

FALCONER, D. S. 1981. Introduction to Quantitative Genetics, 2nd edn. Longman, London.

FISHER, R. A. AND MACKENZIE, W. A. 1923. Studies in crop variation. 2. The manurial response of different potato varieties. J. Agric. Sci. Camb., 13, 311-320.

FREEMAN, G. H. 1973. Statistical methods for the analysis of genotype-environment interactions. Heredity, 31, 339-354.

GALE, M. D. AND GREGORY, R. S. 1977. A rapid method for early generation selection of dwarf genotypes in wheat. Euphytica, 26, 733-738.

GALE, M. D. AND yOUSSEFIAN, S. 1983. Pleiotropic effects of the Norin 10 dwarfing genes, $R h t l$ and $R h t 2$ and interactions in response to chlormequat. In: Proceedings of the Sixth International Wheat Genetics Symposium, pp. 271-277. Kyoto, Japan.

GALE, M. D. AND YOUSSEFIAN, s. 1985. Dwarfing genes in wheat. In: Russel, G. E. (ed.) Progress in Plant Breeding, pp. 1-35. Butterworth, London.

HENDERSON, R. H. 1984. Applications of Linear Models in Animal Breeding. University of Guelph, Canada.

MATHER, K. AND Jinks, J. L. 1971. Biometrical Genetics, 2nd edn. Chapman and Hall, London.

PINTHUS, M. J. 1968. Effects of different applications of CCC (2-chloroethyl trymethyl-ammonium chloride) on heading and culm characters of wheat. Advanc. Front. Plant Sci., 21, 117-126.

ROBERTS, J. A. AND HOOLEY, R. 1988. Plant Growth Regulators. Chapman and Hall, New York.

SAS INSTITUTE INC. 1985. SAS User Guide: Statistics, version 5. SAS Institute Inc, Cary NC. 